Bio-grafía. Escritos sobre la Biología y su Enseñanza. ISSN 2027-1034

Número Extraordinaria. p.p. 241-248

Memorias del Primer encuentro ambiental Universidad, ambiente y sustentabilidad: experiencias y prácticas.

\title{
LA CARA OCULTA DEL ACTIVISMO AMBIENTAL EN LA UPN: CRONOLOGIA DE EXPERIENCIAS
}

\section{Carlos Galvis Riaño ${ }^{1}$}

\section{Resumen:}

Se presenta un escrito a manera de relato en el cual autor describe y lleva a la reflexión sobre algunas de sus experiencias vividas como miembro de la comunidad universitaria de la UPN, quien, a lo largo de varios años, se intereso por participar y compartir con estudiantes y docentes de la institución en acciones que tenían como sentido común la relación con la naturaleza y el medio ambiente. El autor describe de manera cronológica algunas de esas actividades que se desarrollaron en la Universidad, desconocidas por muchos, y que en alguna medida han servido como antecedente para la construcción del sentido ambiental en la UPN.

\section{Abstract:}

We present a brief as a story in which the author describes and leads to reflection on some of his experiences as a member of the university community of the UPN, who over several years, was interested in participating and sharing with students and teachers of the institution in actions that had as common sense the relationship with nature and the environment. The author describes in a chronological way some of those activities that were developed in the University, unknown by many, and that to some extent have served as antecedent for the construction of the environmental sense in the UPN.

${ }^{1}$ Egresado Maestría en Educación - Universidad Pedagógica Nacional

Correo:cgalvis@pedagogica.edu.co 
Bio-grafía. Escritos sobre la Biología y su Enseñanza. ISSN 2027-1034

Número Extraordinaria. p.p. 241-248

Memorias del Primer encuentro ambiental Universidad, ambiente y sustentabilidad: experiencias y prácticas.

Palabras Clave: Activismo ambiental, Cultura ambiental, Educación Ambiental

\section{INTRODUCCIÓN:}

Durante muchos años el tema ambiental en la UPN ha sido un asunto marcado por la indiferencia y el desinterés que la mayoría de los miembros de la comunidad universitaria le han demostrado. Pese a ello, hay quienes en la Universidad creen que lo ambiental es una cuestión de reflexión que debe entenderse y comprenderse, y por lo tanto abordarse.

Ha sido común ver o escuchar al interior del claustro universitario, a grupos o personas convocando e invitando la participación de estudiantes, profesores o administrativos en actividades concretas en referencia a lo ambiental. Algunas de estas acciones se han concentrado en incentivar la actividad física para mejorar la calidad de vida y propiciar espacios para la interacción social con lo natural, otros en el desarrollo de acciones específicas para la resolución de problemas asociados a nuestros malos hábitos y falta de interés por mantener condiciones de vida mínimas, y algunos buscando los momentos y los escenarios para la socialización de experiencias que en el ámbito académico e investigativo se desarrollaron.

Muchas de estas experiencias de participación se dieron de manera personal, desarticulada y aislada, que simplemente pasaron como algo en un momento determinado, con sentido activista, pero de igual manera con ese valor significativo que ha engrandecido la memoria institucional $y$ cultivado el sentido de pertenencia y responsabilidad ambiental. 
Bio-grafía. Escritos sobre la Biología y su Enseñanza. ISSN 2027-1034

Número Extraordinaria. p.p. 241-248

Memorias del Primer encuentro ambiental Universidad, ambiente y sustentabilidad: experiencias y prácticas.

El presente escrito recoge de manera cronológica la descripción de una experiencia de participación del autor en actividades ambientales realizadas en la Universidad durante los últimos años, que desde el activismo y a juicio suyo, alimentó y aportó en alguna medida el sentido ambiental de la Universidad, y que, aunque es un antecedente desconocido y ajeno para muchos, es un elemento más para la construcción de la Dimensión Ambiental de la UPN.

\section{DESARROLLO:}

Cronología ambiental es el acumulado de una serie de experiencias que el autor ha vivenciado a lo largo de 20 años como miembro activo de la Universidad Pedagógica Nacional, en temas relacionados con el llamado activismo ambiental, que no son otra cosa más que todas aquellas acciones e intervenciones que personas o grupos de personas de la comunidad universitaria han realizado en un intento por trabajar en pro de la formación ambiental y generación de cultura para el cuidado del entorno social y natural de la Universidad. Lo cierto es que muchas de esas actividades fueron fugaces, desconocidas o pasaron desapercibidas en nuestro claustro universitario, dejando como siempre el sin saber de que en la Universidad es poco lo que se hace o se ha hecho durante este tiempo por el ambiente.

A lo largo de los años, muchos integrantes de la comunidad universitaria hemos visto como desde la Universidad se ha intentado definir un modelo participativo e integral para vincular a la comunidad universitaria en el desarrollo de actividades que motiven la reflexión y generación de cultura ambiental. Desafortunadamente lo que se ha hecho, ha sido muy 
Bio-grafía. Escritos sobre la Biología y su Enseñanza. ISSN 2027-1034

Número Extraordinaria. p.p. 241-248

Memorias del Primer encuentro ambiental Universidad, ambiente y sustentabilidad: experiencias y prácticas.

sectorizado y particular, evidenciándose un dominio disciplinar, y enfocado principalmente en el desarrollo de actividades propiamente académicas.

Sin embargo, hay quienes han creído que, a pesar de la desarticulación del accionar ambiental en la UPN, es posible trabajar por un bien común, buscar el disfrute y el bienestar a través de actividades que conlleven a la comunidad universitaria a entender nuestra relación con la naturaleza y motivar en ellos el respeto por lo vivo, por las culturas y formas de pensamiento en los diferentes contextos y escenarios sociales y naturales.

El activismo ambiental en la UPN, aunque no lo pareciera, se ha mantenido constante, ha tomado caminos diferentes, pero en alguna medida articulantes. Periódicamente vemos o escuchamos sobre las buenas intenciones que uno $u$ otro programa, o grupos de personas hacen para resaltar la necesidad de abordar la realidad ambiental. Sin lugar a dudas, el trabajo más sobresaliente lo ha tenido la academia, mediante la divulgación o socialización de resultados de trabajos y publicaciones producto del ejercicio investigativo.

Cabe destacar también, el activismo de la gestión administrativa, con la definición de políticas y reglamentaciones internas paulatinamente implementadas, y con una y otra acción localizada de mejoramiento y recuperación de áreas verdes y campañas ecológicas. Finalmente, aquellas actividades que emprendieron ciertos actores en la vida universitaria, que con la búsqueda de protagonismo o sentido ecologista, intervinieron en el devenir institucional generando repulsión, preocupación o reflexión en torno al tema ambiental. 
Bio-grafía. Escritos sobre la Biología y su Enseñanza. ISSN 2027-1034

Número Extraordinaria. p.p. 241-248

Memorias del Primer encuentro ambiental Universidad, ambiente y sustentabilidad: experiencias y prácticas.

Esta última, a juicio del autor, es la que más impacto ha tenido en la vida universitaria, puesto que, a través de ella, es que hemos logrado consolidar una cultura ambiental para la Universidad, desafortunadamente este aspecto desconocido y aislado requiere sostenerse y reconocerse, de tal manera que todos conozcamos como es que se lleva a cabo la actividad ambiental en la UPN.

El accionar ambiental, de acuerdo con esta cronología, comenzó a darse a finales de los años noventa en escenario que marco la vida de estudiantes, profesores y administrativos de aquella época. Las llamadas caminatas ecológicas, organizadas por la Subdirección de Bienestar Universitario, y dirigida por un docente de la Facultad de Educación Física, figuraron como un atractivo de recreación y ocio, las que, durante tres años, permitió a los asistentes de diferentes dependencias, compartir experiencias y alegrías, aprendiendo a admirar y respetar la naturaleza, y motivando la generación de una nueva cultura ambiental en la UPN.

Finalizado los años 90, la Universidad entró en una especie de reconciliación con la naturaleza. Impulsado por el Departamento de Biología, se organizó el primer grupo de amigos de los artrópodos "Entomófilos", abierto a los miembros de la comunidad universitaria interesados en los insectos. Unos años más tarde el mismo Departamento, organizó el /l Curso Internacional Educación para la Conservación y Manejo Sostenible de los Recursos Acuáticos Continentales del Neotrópico, apoyado por la OEA, en el cual tuvimos la fortuna de participar y compartir los miembros de la comunidad universitaria interesados en conocer sobre la importancia del recurso agua en el país y en Latinoamérica. En el evento se compartió con asistentes de otras instituciones nacionales e internacionales. 
Bio-grafía. Escritos sobre la Biología y su Enseñanza. ISSN 2027-1034

Número Extraordinaria. p.p. 241-248

Memorias del Primer encuentro ambiental Universidad, ambiente y sustentabilidad: experiencias y prácticas.

Los inicios de la década del 2000 marco para la Universidad un interesante momento, pues se firmó un Convenio con el Jardín Botánico de Bogotá José Celestino Mutis con el fin de de desarrollar un proyecto administrativo, denominado Arborización Urbana en contextos Universitarios en el cual se esperaba mejorar y recuperar los espacios verdes del claustro universitario, y para su desarrollo se contó con la participación nuevamente de estudiantes y personal administrativo de diferentes instancias.

Otro evento de vital relevancia para la institución tuvo que ver con el proyecto de Extensión denominado Evaluación del componente pedagógico del Programa de Agricultura Urbana del Jardín Botánico José Celestino Mutis. Proyecto que fue financiado por la Red de Jardines Botánicos de Colombia, y administrado en el año 2006 por la División de Asesorías y Extensión de la UPN, y en el cual participaron estudiantes del Departamento de Biología y de Psicopedagía (Reyes y Galvis, 2007).

Un hecho sin precedentes para la vida universitaria tuvo que ver con la organización e implementación de un esquema de gestión ambiental, que, durante cinco años, funcionó como un proceso sistémico para vincular el accionar ambiental a través de mecanismos de planeación, ejecución e implementación de políticas y reglamentos para organizar las actividades de la Universidad. El proceso se conoció como el Sistema de Administración Ambiental de la UPN, creado para integrar las actividades de gestión académica, administrativa y de investigación, y el cual actualmente sigue en desarrollo, y es una importante base para consolidar la dimensión ambiental en la UPN.

Una experiencia muy significativa para el autor, tuvo que ver con su participación en proyectos de innovación pedagógica desarrollados con los niños del Instituto Pedagógico Nacional. En el año 2012 se llevó a cabo el 
Bio-grafía. Escritos sobre la Biología y su Enseñanza. ISSN 2027-1034

Número Extraordinaria. p.p. 241-248

Memorias del Primer encuentro ambiental Universidad, ambiente y sustentabilidad: experiencias y prácticas.

proyecto "La observación de aves como estrategia de educación ambiental para niños" trabajo que fue socializado en un Congreso Internacional llevado en Salta - Argentina (Galvis y Tovar, 2012), y en el 2013 se realizó el proyecto "Técnicas de supervivencia y convivencia para niños en contextos naturales".
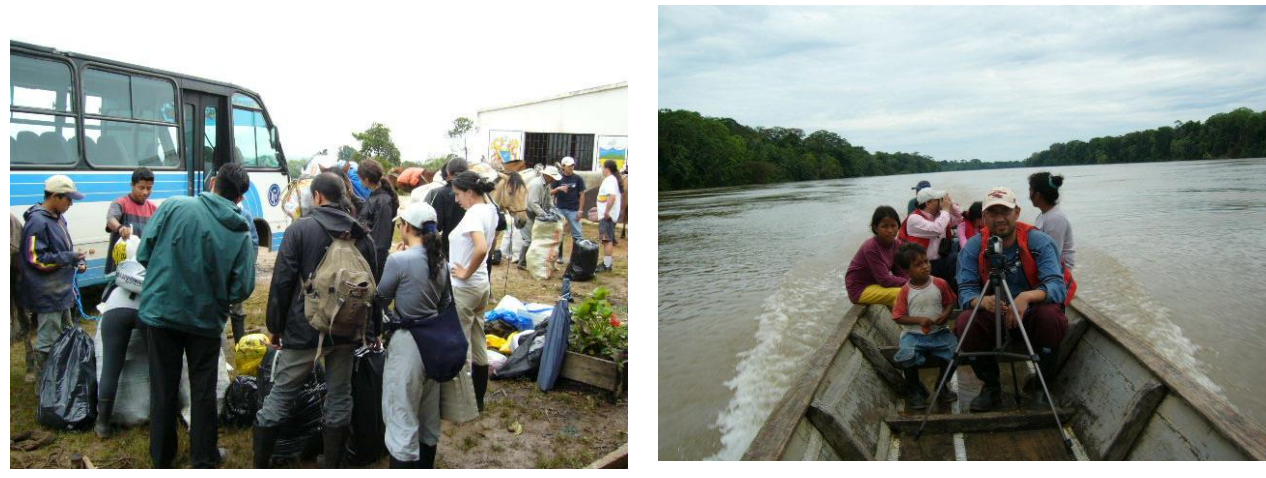

El autor acompañando algunas actividades académicas de campo realizadas por estudiantes del Departamento de Biología en el PNN Cueva de los Guacharos en el año 2005, foto izquierda, y por profesores del Departamento de Posgrados en la Región del Araracuara en el año 2007, foto derecha.

Todas estas actividades que se resaltaron a lo largo del documento, son un ejemplo de muchos otros, sobre lo que se puede hacer y trabajar conjuntamente entre miembros de la comunidad universitaria, indistintamente del tipo de relación que se tenga con la UPN. Las experiencias de activismo son la muestra de que en la Universidad se cuenta con historia y antecedentes que pueden direccionar la construcción del Marco de la Dimensión Ambiental de la UPN. 
Bio-grafía. Escritos sobre la Biología y su Enseñanza. ISSN 2027-1034

Número Extraordinaria. p.p. 241-248

Memorias del Primer encuentro ambiental Universidad, ambiente y sustentabilidad: experiencias y prácticas.

\section{REFERENCIAS:}

Galvis, C. y Tovar, D. (2012). La observación de aves como estrategia de educación ambiental para niños y jóvenes. Memorias Décimo Congreso Internacional de Manejo de Fauna Silvestre y Comunidades Rurales. Universidad de Salta - COMFAUNA. Salta (Argentina). http://comfauna.org/3-educacion-como-herramientapara-la-conservacion-salta-argentina-2012/.

Reyes, M. y Galvis, C. (2007). Informe: Evaluación del componente pedagógico del proyecto de Agricultura Urbana del Jardín Botánico de Bogotá José Celestino Mutis. Universidad Pedagógica Nacional - Red de Jardines Botánicos de Colombia. Bogotá, 114 p. 